\title{
UNIVERSAL CURRENT-CONVEYOR-BASED CURRENT-MODE FILTERS WITH SINGLE INPUT AND THREE OUTPUTS
}

\author{
MUHAMMAD TAHER ABUELMA'ATTI* \\ and AMIR ALAM FAROOQUI \\ King Fahd University of Petroleum and Minerals, Box 203, \\ Dhahran 31261, Saudi Arabia
}

(Received 28 December 1996; In final form 13 March 1997)

\begin{abstract}
Universal active current-mode filters with single input and three outputs are presented. The proposed filters avoid the use of external feedback in any part of the circuit and use grounded resistors and grounded capacitors. The proposed circuits can simultaneously realize lowpass, highpass, and bandpass filter functions.
\end{abstract}

Keywords: Active filters; current conveyors

\section{INTRODUCTION}

At present there is a growing interest in designing current-mode current-conveyor-based active filters. This is attributed to their higher signal bandwidths, greater linearity and larger dynamic range [1]. Thus a number of circuit realizations for universal current-mode filters were proposed [2-11]. A critical study shows that some of these circuits use grounded resistors and capacitors [2-7], other circuits use floating resistors and/or capacitors [8-11]. The majority of the proposed circuits can realize the basic biquadratic filter functions that is lowpass, highpass and bandpass. Moreover, most of the circuits employ external feedback in part of the circuit in order to realize the

*Corresponding author. 
transfer functions required. This may result in instability problems especially at high frequencies where the nonidealities of the currentconveyors cannot be ignored.

As an illustrative example, consider the most-recent circuit proposed by Chang [2]. This circuit uses different types of current conveyors, $\mathrm{CCI}-, \mathrm{CCI}+, \mathrm{CCII}-$ and $\mathrm{CCII}+$. While the circuit has the advantage of using grounded resistors and capacitors, it employs external feedback in part of it.

In order to avoid the possible instability problems that may arise due to the employment of external feedback, it is necessary to avoid using external feedback throughout the whole circuit. Also it would be attractive for integration if a proposed implementation, avoiding the employment of external feed back, can be realized using grounded resistors and capacitors. It is the purpose of this paper to present such a realization.

\section{PROPOSED CIRCUITS}

The proposed circuits are shown in Figure 1. Using the standard notations the characteristics of the current conveyors can be described by $i_{x}=i_{z}, i_{y}=0, v_{x}=v_{z}$ for the CCII + and $i_{x}=i_{y}=i_{z}, v_{x}=v_{y}$ for the $\mathrm{CCI}+$. Routine analysis of the circuit yields the following transfer functions

$$
\begin{gathered}
\frac{I_{L}}{I_{i}}=\frac{1 / \alpha_{L}}{s^{2}+\frac{\omega_{o}}{Q_{o}} s+\omega_{o}^{2}} \\
\frac{I_{B}}{I_{i}}=\frac{s / \alpha_{B}}{s^{2}+\frac{\omega_{o}}{Q_{o}}+\omega_{o}^{2}}
\end{gathered}
$$

and

$$
\frac{I_{H}}{I_{i}}=\frac{s^{2} / \alpha_{H}}{s^{2}+\frac{\omega_{o}}{Q_{o}}+\omega_{o}^{2}}
$$




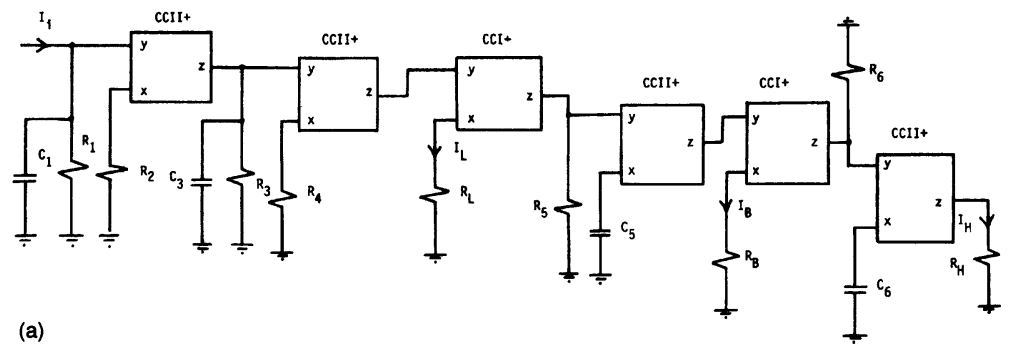

(a)

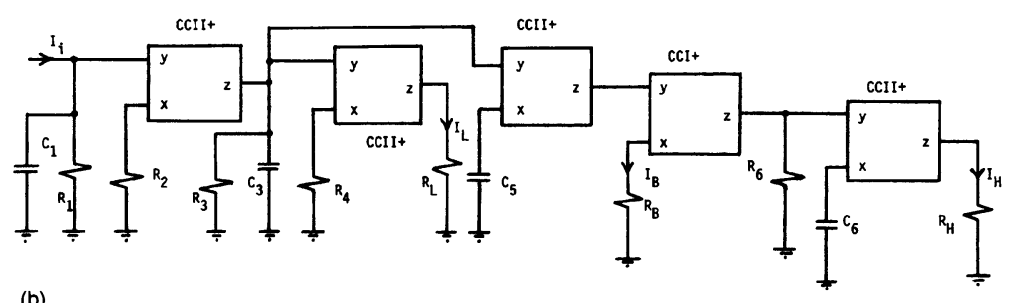

(b)

FIGURE 1 Proposed current-mode universal filters.

where the parameters $\alpha_{L}, \alpha_{B}, \alpha_{H}, \omega_{o}, \frac{\omega_{o}}{Q_{o}}$ are given by

$$
\begin{aligned}
\alpha_{L} & =-C_{1} C_{3} R_{2} R_{4} \\
\alpha_{B} & =C_{1} C_{3} R_{2} R_{4} / C_{5} R_{5} \\
\alpha_{H} & =C_{1} C_{3} R_{2} R_{4} / C_{5} C_{6} R_{5} R_{6} \\
\omega_{o}^{2} & =1 / C_{1} C_{3} R_{1} R_{3} \\
\frac{\omega_{o}}{Q_{o}} & =1 / C_{1} R_{1}+1 / C_{3} R_{3}
\end{aligned}
$$

for the circuit of Figure 1a, and are given by

$$
\begin{aligned}
\alpha_{L} & =C_{1} C_{3} R_{2} R_{4} \\
\alpha_{B} & =-C_{1} C_{3} R_{2} / C_{5} \\
\alpha_{H} & =-C_{1} C_{3} R_{2} / C_{5} C_{6} R_{6} \\
\omega_{o}^{2} & =1 / C_{1} C_{3} R_{1} R_{3} \\
\frac{\omega_{o}}{Q_{o}} & =1 / C_{1} R_{1}+1 / C_{3} R_{3}
\end{aligned}
$$

for the circuit of Figure 1b. 
Equation (1) corresponds to the transfer function of a lowpass filter, Eq. (2) corresponds to the transfer function of a bandpass filter and Eq. (3) corresponds to the transfer function of a highpass filter.

From (4)-(7) one can see that the parameters $\omega_{o}$ and $\frac{\omega_{o}}{Q_{o}}$ can be adjusted by tuning grounded resistors and/or capacitors.

\section{SIMULATION RESULTS}

To verify their operation, the proposed circuits have been simulated using Pspice. The CCII \pm has been simulated using an operational amplifier together with current mirrors composed of transistor arrays [12] and the CCI- has been simulated using the translinear CC implementation [13]. The results obtained from the lowpass and the bandpass filters are shown in Figures 2 and 3. These results are in good agreement with the theory.

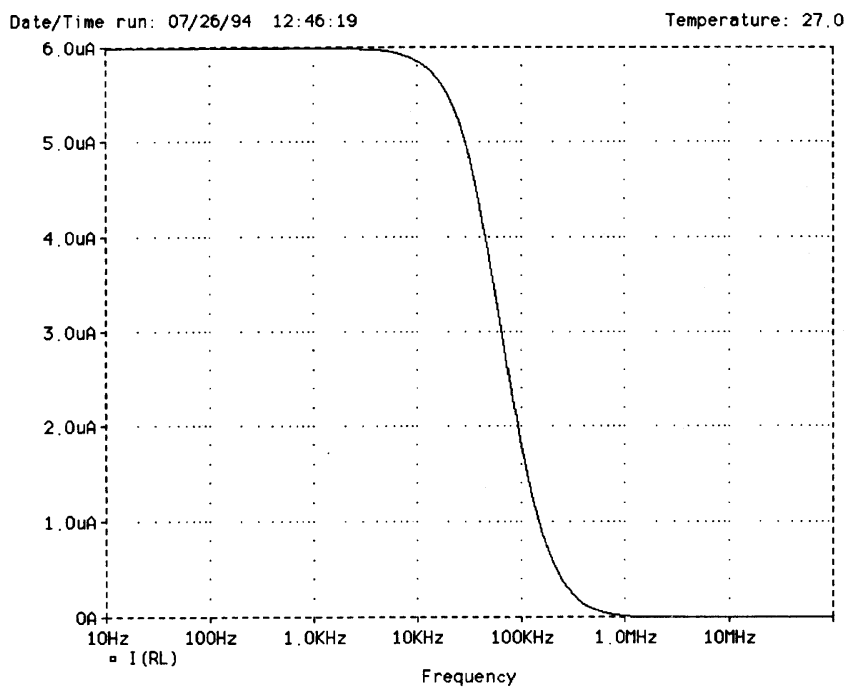

FIGURE 2 Simulated lowpass characteristics obtained from Figure 1a with $R_{1}=12 \mathrm{~K}$, $R_{2}=1 \mathrm{~K}, R_{3}=10 \mathrm{~K}, R_{4}=100 \mathrm{~K}, R_{L}=1 \mathrm{~K}, C_{1}=C_{3}=220 \mathrm{PF}$. 


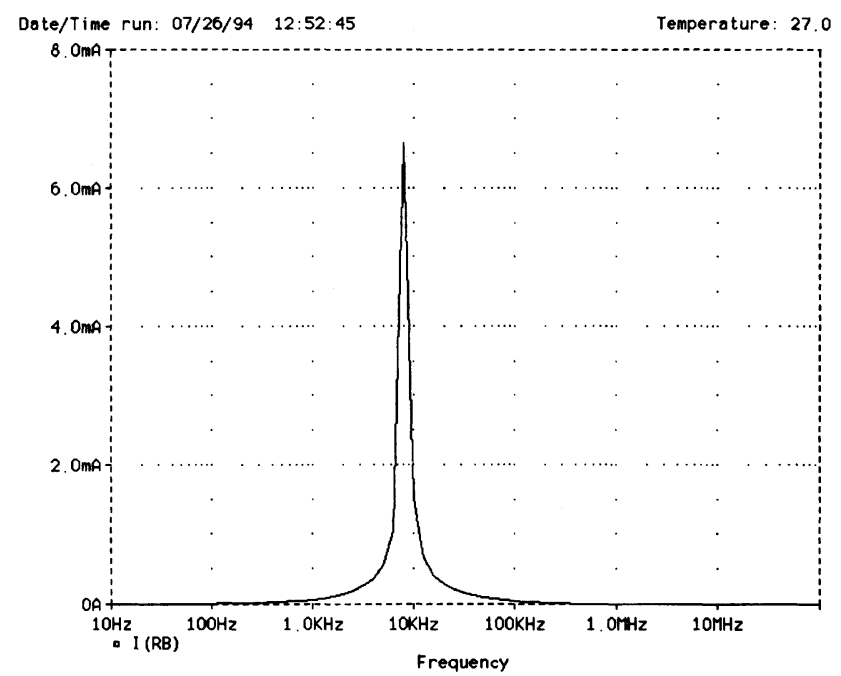

FIGURE 3 Simulated bandpass characteristics obtained from Figure 1b with $R_{1}=$ $R_{3}=10 \mathrm{~K}, R_{2}=R_{5}=R_{6}=R_{B}=R_{L}=1 \mathrm{~K}, R_{4}=100 \mathrm{~K}, C_{1}=C_{3}=2.2 \mathrm{PF}, C_{5}=2.2$ NF.

\section{CONCLUSION}

In this paper two universal current-mode filters using currentconveyors have been presented. The first circuit uses five current conveyors and the second circuit uses six current conveyors. Both circuits can simultaneously realize the three standard biquadratic functions; the lowpass, the highpass and the bandpass filters. The parameters of the realized filters can be adjusted by tuning grounded resistors and/or capacitors.

\section{References}

[1] Roberts, G. W. and Sedra, A. S. (1989). All current-mode frequency selective circuits, Electroncis Letters, 25, pp. 759-761.

[2] Chang, C.-M. (1993). Novel universal current-mode filter with single input and three outputs using only five current conveyors, Electronics Letters, 29, pp. 2005-2007.

[3] Chang, C.-M. (1993). Universal active current filter with single input and three outputs using CCIIs, Electronics Letters, 29, 1932-1933.

[4] Chang, C.-M. and Chen, P.-C. (1991). Universal active current filter with three inputs and one output using current conveyors, International Journal of Electronics, 71, pp. 817-819. 
[5] Chang, C.-M. and Chen, P.-C. (1991). Realization of current-mode transfer function using second-generation current conveyors, International Journal of Electronics, 71, pp. 805-815.

[6] Sun, Y. and Fidler, J. K. (1994). Versatile active biquad based on secondgeneration current conveyors, International Journal of Electroncis, 76, pp. 91-98.

[7] Chang, C.-M., Chien, C.-C. and Wang, H.-Y. (1994). Universal active current filter with three inputs using current conveyors-Part 2, International Journal of Electronics, 76, pp. 87-89.

[8] Chang, C.-M. (1993). Current-mode lowpass, bandpass and highpass biquads using two CCIIs, Electronic Letters, 29, pp. 2020-2021.

[9] Chang, C.-M. (1991). Universal active current filters using single secondgeneration current conveyor, Electronic Letters, 27, pp. 1614-1617.

[10] Chang, C.-M., Chien, C.-C. and Wang, H.-Y. (1993). Universal active current filters using single second-generation current conveyor, Electroncis Letters, 29, pp. $1159-1160$.

[11] Wu, D.-S., Hwang, Y.-S., Liu, S.-I. and Wu, Y.-P. (1994). New multifunction filter using an inverting CCII and a voltage follower, Electronics Letters, 30, pp. $551-552$.

[12] Wilson, B. (1984). High-performance current conveyor implementation, Electronics Letters, 20, pp. 990-991.

[13] Fabre, A. (1984). Wideband translinear current conveyor, Electronics Letters, 20, pp. $241-242$. 

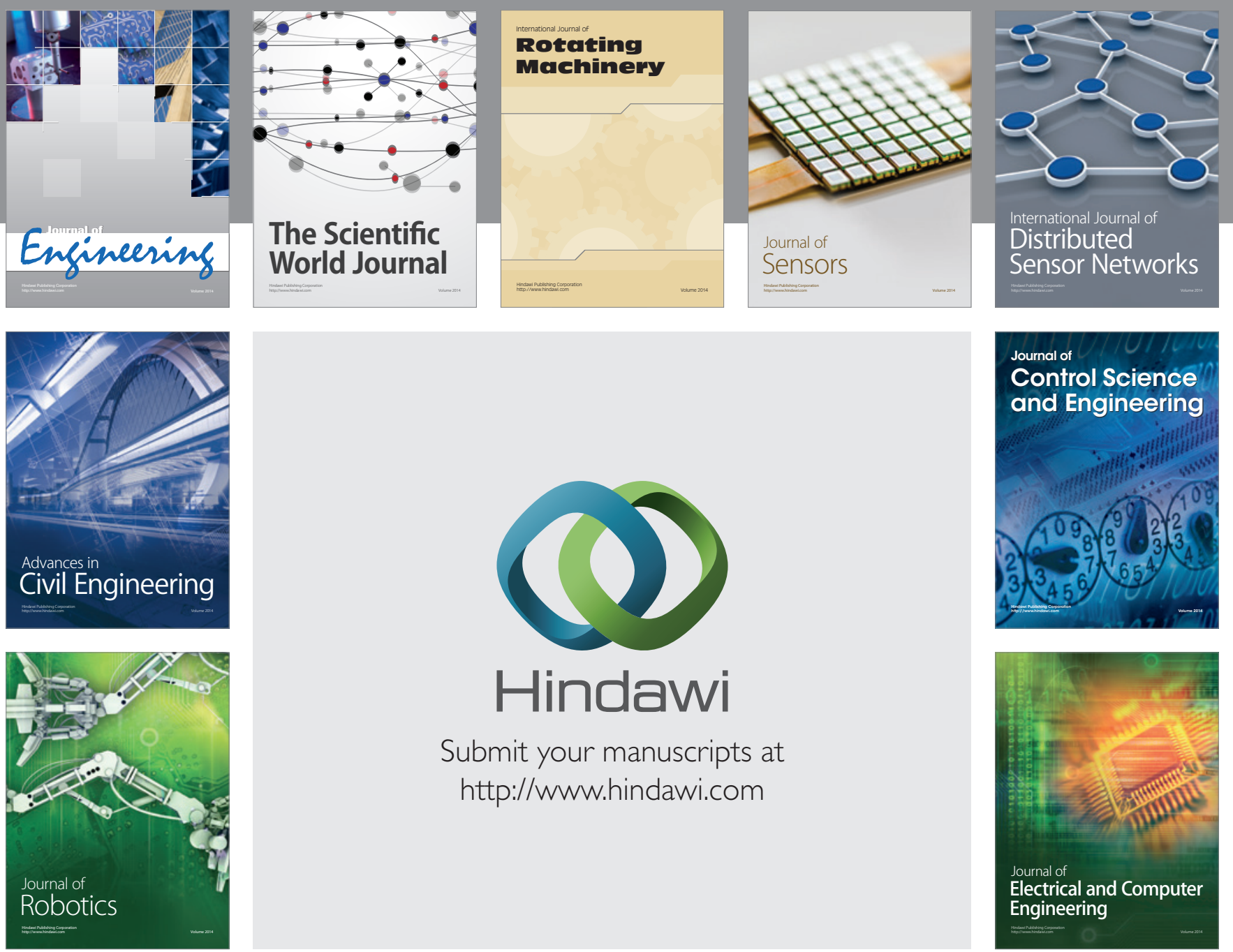

Submit your manuscripts at

http://www.hindawi.com
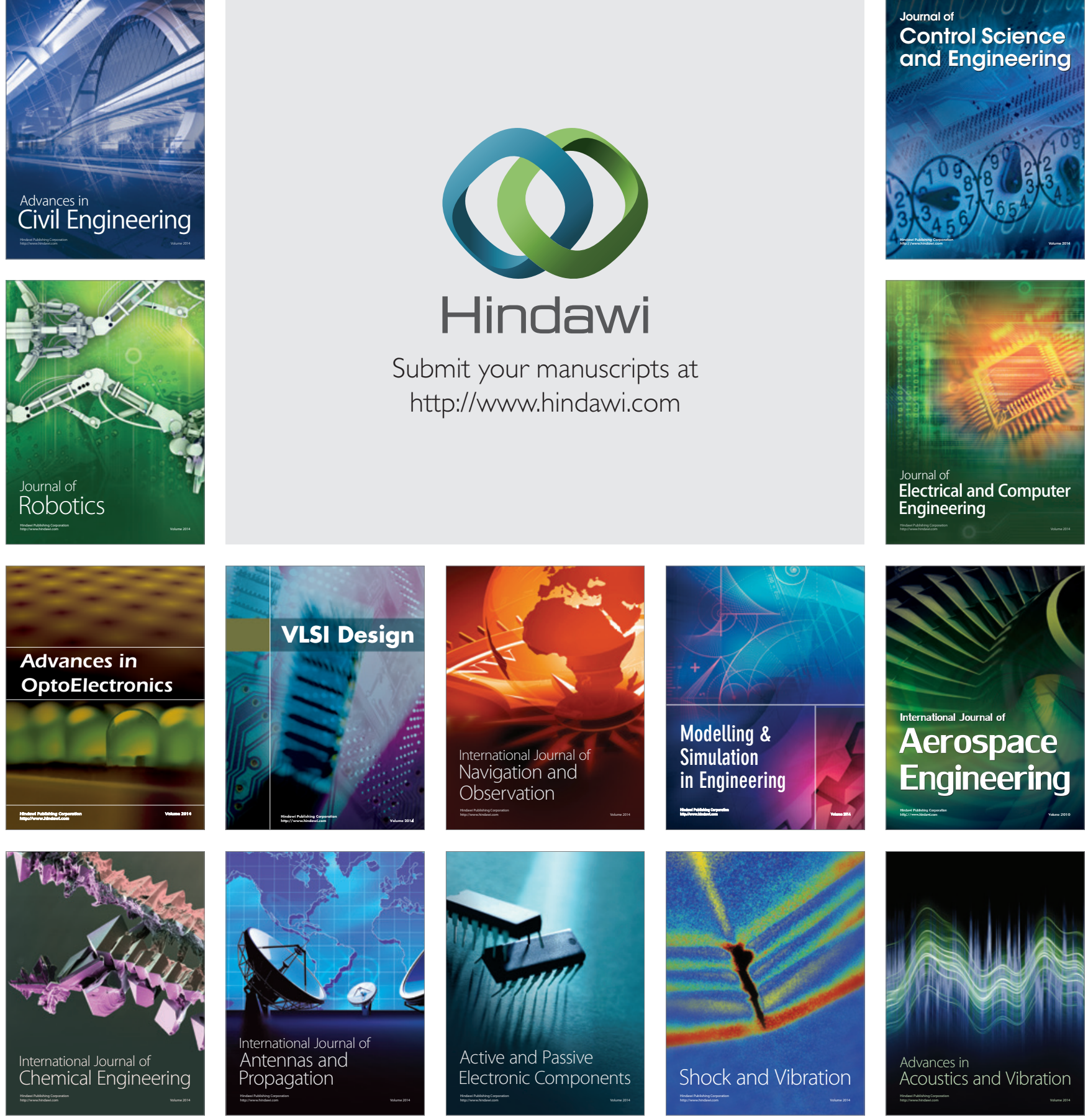